\title{
ESTIMACIÓN DE LA RIQUEZA DE ESPECIES DE ASTERACEAE MEDIANTE EXTRAPOLACIÓN A PARTIR DE DATOS DE PRESENCIA-AUSENCIA
}

\author{
José Luis Villaseñor', Pedro Maeda², J. Javier Colín-LóPez² y Enrique Ortiz \\ 1 Instituto de Biología, Universidad Nacional Autónoma de México, Departamento de Botánica, Apartado Postal 70- \\ 233, C.P. 04510, Delegación Coyoacán, México, D.F., México. Correo-e: vrios@ibiologia.unam.mx. \\ ${ }^{2}$ Comisión Nacional para el Conocimiento y Uso de la Biodiversidad. Liga Periférico-Insurgentes Sur 4903, Parques \\ del Pedregal, C.P. 14010, Delegación Tlalpan, México, D.F., México.
}

\begin{abstract}
Resumen: Se estimaron los patrones de riqueza en México de cuatro tribus de la familia Asteraceae del país que recientemente han sido revisadas (Mutisieae, Senecioneae, Tageteae y Vernonieae) mediante extrapolación, utilizando datos de las etiquetas de ejemplares de herbario. Se utilizó el método de estimación de riqueza no paramétrico ICE ("Incidence-based Coverage Estimator"), el cual se basa en datos de presencia-ausencia de las especies por área. Se evaluaron 553 especies, que representan 18.3\% de la riqueza de Asteraceae presente en México, representadas por 24,304 registros de herbario recolectados en 14,714 diferentes localidades. La información fue analizada dividiendo al país en cuadrículas con celdas de $1^{\circ}$ de latitud y longitud y con celdas de $0.5^{\circ}$. Se identificaron las celdas con alta riqueza conocida (hot spots), así como aquellas que la extrapolación sugiere que contienen una alta riqueza estimada. Se determinaron las que parecen ameritar mayor atención en futuros trabajos de exploración, utilizando las diferencias entre la riqueza estimada y la observada para cada celda, con base en el supuesto teórico de que el valor estimado es más cercano al valor real.
\end{abstract}

Palabras clave: biodiversidad vegetal, estimación, ICE, México, riqueza de especies.

\begin{abstract}
Using label data of herbarium specimens of Mexican species belonging to four recently revised tribes of the family Asteraceae (Mutisieae, Senecioneae, Tageteae, and Vernonieae), richness patterns in the country of these tribes were estimated through extrapolation. The ICE ("Incidence-based Coverage Estimator") non-parametric estimation technique, which is based on presence-absence data of species by area unit, was used. In total 553 species were analyzed; they account for $18.3 \%$ of the total Asteraceae species richness of Mexico and were represented by 24,304 specimen records from 14,714 different localities. Information for species was analyzed by dividing the country in cells or grid-squares of $1^{\circ}$ latitude and longitude, and cells of $0.5^{\circ}$. The cells with the highest known species richness (hot spots) were identified, as well as those suggested by extrapolation as having a high estimated richness. Using the differences between estimated and observed richness by cell, those pinpointed as requiring urgent attention for future fieldwork were determined; they are considered to be important assuming that they include a proportionally larger number of species than those presently known, according to their estimated richness.
\end{abstract}

Key words: plant biodiversity, estimation, ICE, Mexico, species richness.

C onocer la magnitud de la biodiversidad de un sitio, país o región es parte fundamental de las actividades de los biólogos. El conocimiento de la riqueza de especies, por ejemplo, ha sido uno de los parámetros determinantes para definir las acciones sugeridas por la biología de la conservación (Petersen et al., 2003).

El conocimiento de la magnitud de la biodiversidad se ha obtenido rutinariamente a través de exploraciones sis- temáticas y de muestras que se procesan y resguardan en herbarios y museos. Desafortunadamente este proceso demanda mucho tiempo (años o inclusive siglos) y recursos, tanto económicos como humanos. Será entonces difícil confiar a la exploración rutinaria, como ha sido llevada a cabo hasta la fecha, la adquisición de los datos básicos para presentar un escenario adecuado de nuestra biodiversidad (Colwell y Coddington, 1994). Algunos autores, por 
José Luis Villaseñor, Pedro Maeda, J. Javier Colín-López y EnRique Ortiz

ejemplo May (1992), Soulé (1990) y Hammond (1992), sugieren que al ritmo en que se ha obtenido el conocimiento existente a la fecha, tardaremos varios siglos en contar con datos satisfactorios. En México, por ejemplo, no obstante ser un país megadiverso (Mittermeier, 1988; Mittermeier y Goettsch, 1992; Villaseñor, 2003), pocos sitios cuentan con inventarios florísticos y/o faunísticos y gran parte de su territorio aún está en fase de exploración para cuantificar sus valores de diversidad (CabreraRodríguez y Villaseñor, 1987; Sosa y Dávila, 1994; Villaseñor, 2004). Para este país, una evaluación reciente de la tasa de publicación de especies nuevas de plantas con flores (J.L. Villaseñor, datos no publicados), revela que durante los últimos 15 años se han publicado en promedio 50 especies nuevas por año. Villaseñor (2003) estimó que tan sólo para Angiospermas, faltan por describir más de 6,000 taxones. Así, con la tasa de descripción actual, para conocer mejor nuestra riqueza florística necesitaremos más de un siglo, suponiendo que antes no se hayan extinguido las especies desconocidas.

Cada vez se hace más patente que al estudiar los patrones de diversidad, rareza y endemismo, la selección de los mejores sitios para la conservación de la biodiversidad se vuelve más eficiente (ver por ejemplo Gaston, 1996). El estudio de los patrones de las plantas vasculares se vuelve particularmente importante, pues además de ser un grupo altamente diversificado en todo el mundo, muestra patrones de endemicidad de gran interés; pero sobre todo, pueden servir como substitutos para entender los patrones de otros grupos, por ejemplo de invertebrados y vertebrados, pues muchas especies de tales grupos de animales utilizan a las plantas vasculares como alimento o como sitios de anidamiento, o viven en microhábitats creados o promovidos por las asociaciones vegetales, mismas que realizan muchas e importantes funciones en los ecosistemas.

La carencia de datos confiables sobre la biodiversidad local y regional ha obligado a los biólogos a formular modelos de extrapolación para estimar los valores de biodiversidad en sitios de interés particular (Palmer, 1990, 1991; Colwell y Coddington, 1994; Fagan y Kareiva, 1997; Murguía y Villaseñor, 2000; Soberón et al., 2000). Existen cuando menos tres procedimientos de extrapolación para estimar la riqueza local de especies (Palmer, 1990; Colwell y Coddington, 1994): uno es mediante curvas de acumulación de especies (por ejemplo Soberón y Llorente, 1993); otro es utilizando métodos paramétricos que analizan tanto la distribución como la abundancia, sobre todo con técnicas que evalúan distribuciones de frecuencias (Log-normal, Poisson-log normal y otros, por ejemplo Fagan y Kareiva, 1997); el tercero es con técnicas de evaluación no paramétricas, basadas en la distribución de los individuos entre las especies o de especies entre muestras o áreas (ver por ejemplo Murguía y Villaseñor, 2000; Soberón et al., 2000; Petersen et al., 2003; Villaseñor, 2003).
En este estudio se analiza un grupo de especies, todas ellas de la familia Asteraceae, registradas en México y cuyos especímenes que documentan su presencia en este territorio han sido identificados y su información taxonómico-geográfica almacenada en una base de datos. El objetivo es evaluar, con base en el uso de métodos no paramétricos, qué tan completo es su inventario a nivel nacional y cuánto trabajo adicional (así como dónde), tendría que hacerse para considerar que sus patrones de riqueza ya se conocen aceptablemente.

\section{Materiales y métodos}

Para estimar los valores de riqueza se utilizaron dos escalas: la primera consistió en dividir al territorio de México en cuadrículas, la primera de $1^{\circ}$ de latitud y longitud y la segunda de $0.5^{\circ}$ de latitud y longitud. Para cada celda se anotó el número de especímenes recolectados, los cuales representaron registros únicos (eliminando duplicados). De esta manera, cada registro difiere ya sea por la fecha de recolecta o representa a una especie diferente en un mismo sitio georreferenciado.

Cada registro fue georreferenciado para ubicar su presencia en las celdas en que fue dividido el país. Los registros representan la distribución conocida de las especies, pertenecientes a las tribus Mutisieae, Senecioneae, Tageteae y Vernonieae (cuadro 1), cuatro de las 14 tribus de Asteraceae que contienen especies en la flora de México (Villaseñor, 1993). Se eligieron estas cuatro tribus debido a que en fechas recientes han sido críticamente revisadas y toda la información taxonómico-geográfica contenida en los especímenes está capturada en una base de datos. La información proviene de la consulta de material herborizado de más de 15 herbarios de México y otras partes del mundo, la cual se puede consultar en la Red Mundial de Información sobre Biodiversidad (REMIB), consultando la página de Internet de la Comisión Nacional para el Conocimiento y Uso de la Biodiversidad (URL: http://www.conabio.gob.mx/remib/doctos/remibnodosdb.html?\#).

Cuadro 1. Número de registros y de especies evaluadas de cuatro tribus de Asteraceae.

\begin{tabular}{lccc}
\hline Tribu & Registros & Especies & Especies endémicas \\
\hline Mutisieae & 2,589 & 115 & 94 \\
Senecioneae & 10,283 & 230 & 169 \\
Tageteae & 8,022 & 141 & 87 \\
Vernonieae & 3,410 & 67 & 45 \\
Total & 24,304 & 553 & 395 \\
\hline
\end{tabular}


Para calcular la riqueza proyectada de especies por celda, se utilizó el estimador ICE ("Incidence-based Coverage Estimator"; Colwell, 1997). Este estimador es apropiado para el tipo de datos analizados, pues solamente requiere de datos de presencia y el algoritmo para su aplicación ya está incorporado en un programa de cómputo. Además, toma en cuenta el sesgo que tienen las bases de datos biológicas, donde se encuentran especies que son muy comunes (con muchos registros) y otras que son muy raras (uno o pocos registros). Igualmente importante es que el ICE permite analizar y sintetizar grandes cantidades de datos que difícilmente se podrían analizar de otra manera.

Al igual que los otros estimadores de riqueza no paramétricos (Palmer, 1990; Colwell y Coddington, 1994), el ICE se basa en el conjunto de especies raras. De hecho, la estimación se obtiene evaluando principalmente al con- junto de especies registradas con 10 o menos recolectas en una localidad o área determinada (es decir, las más raras de la zona de estudio). Sin embargo hay que subrayar que en algunas celdas, a pesar de registrarse muestreos y un número observado de especies, el estimador se indetermina cuando: (a) todas las especies raras o infrecuentes presentan frecuencias igual a uno, (b) sólo se tiene una muestra con especies infrecuentes, y (c) existe una sola muestra o todas las muestras son iguales. Por esta razón, siempre existe un número de celdas en las dos escalas utilizadas sin valor de riqueza estimada, aunque sí presentan una cierta riqueza conocida.

Una vez obtenidos los valores de riqueza estimada por celda para las dos escalas utilizadas, éstos se evaluaron gráficamente para determinar los sitios de alta riqueza de especies (hot spots), tanto conocida como estimada. Con
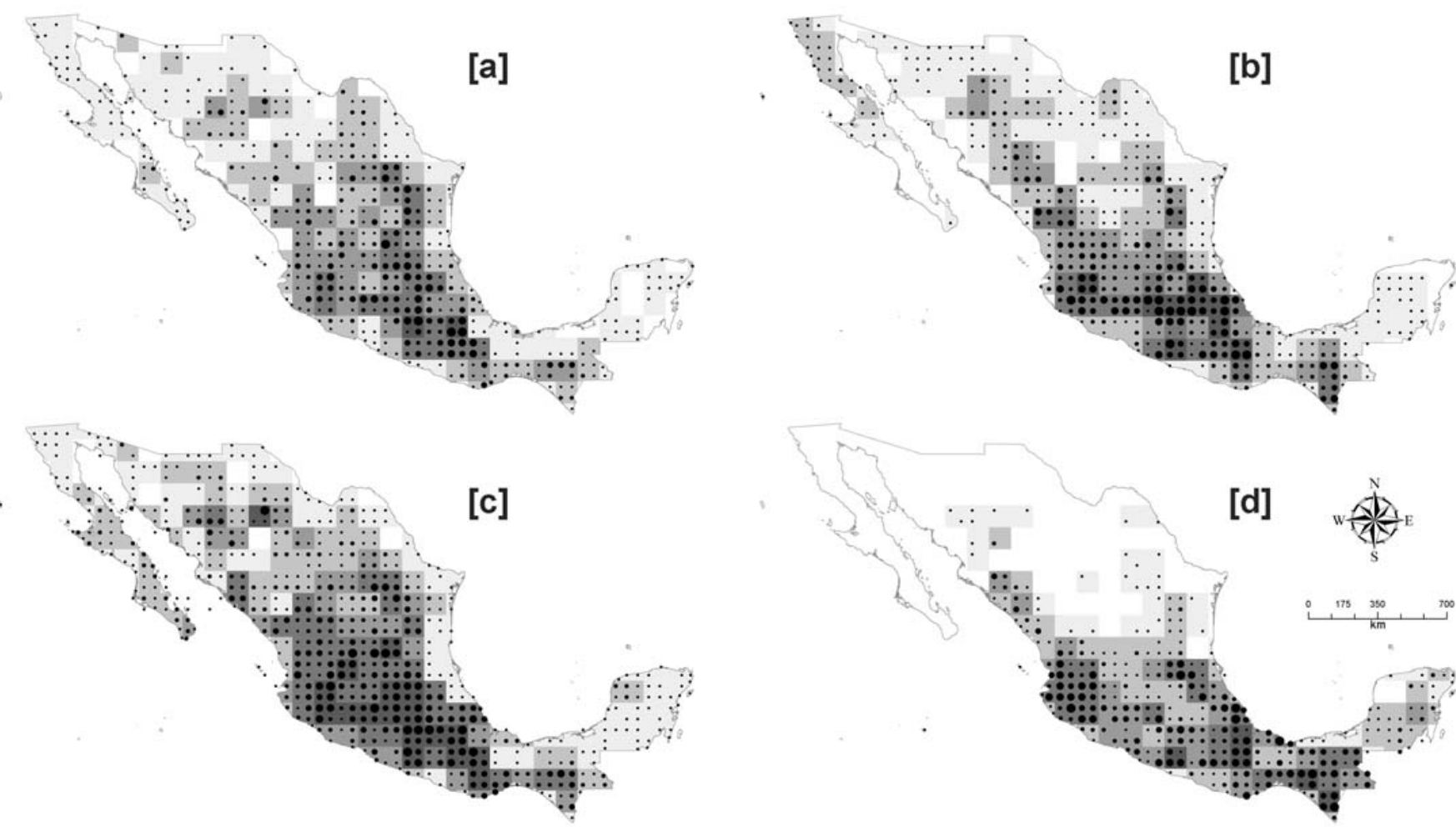

En cuadros de $1^{\circ}$
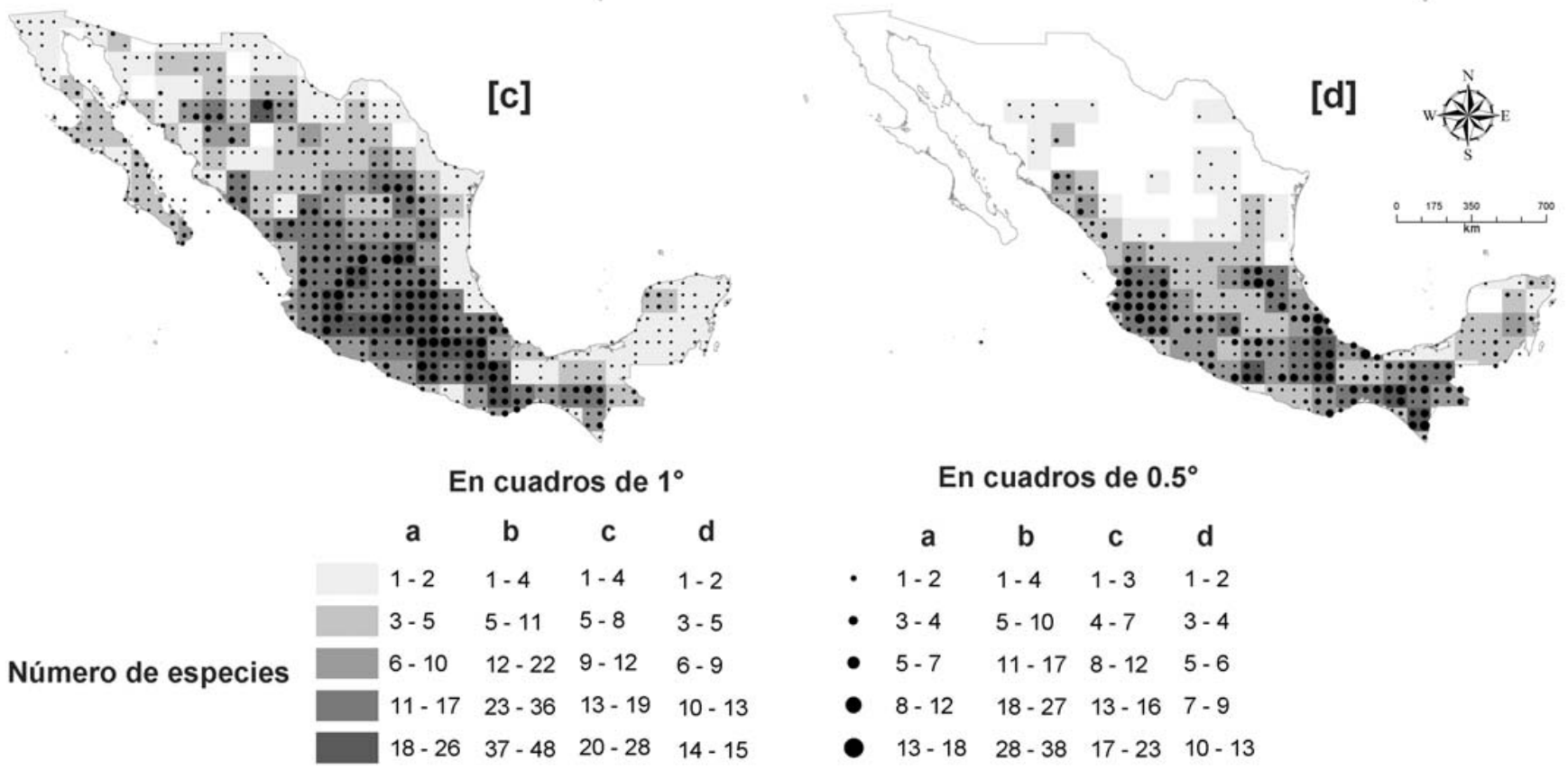

En cuadros de $0.5^{\circ}$

$\begin{array}{ccccl} & \mathbf{a} & \mathbf{b} & \mathbf{c} & \mathbf{d} \\ \text { - } & 1-2 & 1-4 & 1-3 & 1-2 \\ \text { - } & 3-4 & 5-10 & 4-7 & 3-4 \\ \text { - } & 5-7 & 11-17 & 8-12 & 5-6 \\ \text { - } & 8-12 & 18-27 & 13-16 & 7-9 \\ \text { - } & 13-18 & 28-38 & 17-23 & 10-13\end{array}$

Figura 1. Riqueza observada en las tribus de Asteraceae estudiadas: [a] Mutisieae, [b] Senecioneae, [c] Tageteae, [d] Vernonieae. 

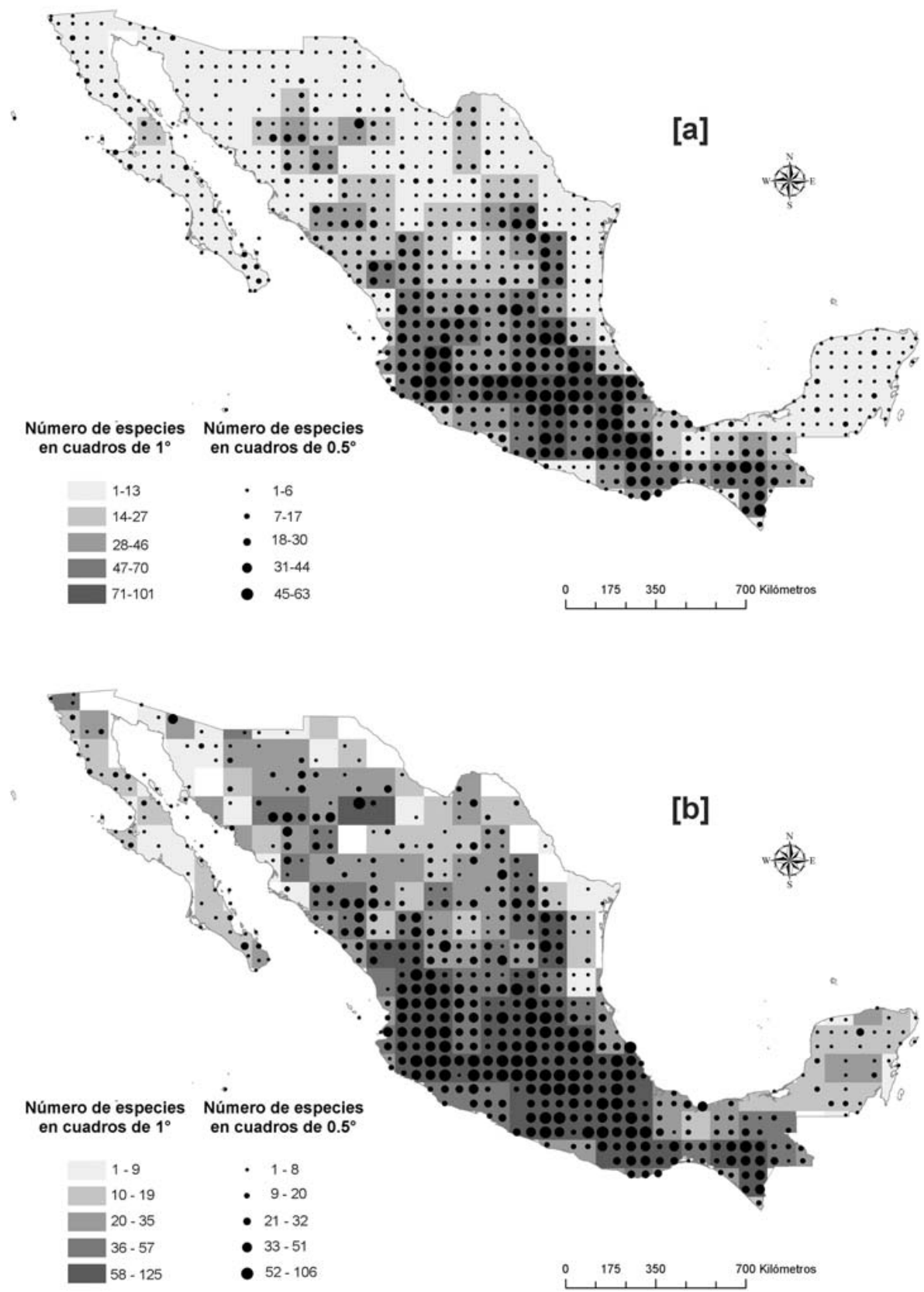

Figura 2. Riqueza observada [a] y riqueza estimada [b] en las cuatro tribus de Asteraceae estudiadas.

ambos valores de riqueza se obtuvo un valor de diferencia, restando a la riqueza estimada la riqueza conocida. Este valor fue utilizado como un criterio para ubicar los sitios que ameritan más atención en futuros trabajos de exploración, pues mientras mayor es la diferencia se infiere, bajo el supuesto de que el valor estimado es más cercano al valor real, que estos sitios contienen un número de especies mayor que las conocidas en la actualidad.

\section{Resultados}

Se evaluaron 24,304 registros que representan la riqueza y distribución conocida de las especies pertenecientes a las tribus Mutisieae, Senecioneae, Tageteae y Vernonieae (cuadro 1). Este número corresponde a 14,714 diferentes localidades únicas, con las que se obtuvieron los registros de incidencia por celda. Las cuatro tribus analizadas incluyen 553 especies (cuadro 1), cifra que equivale a 

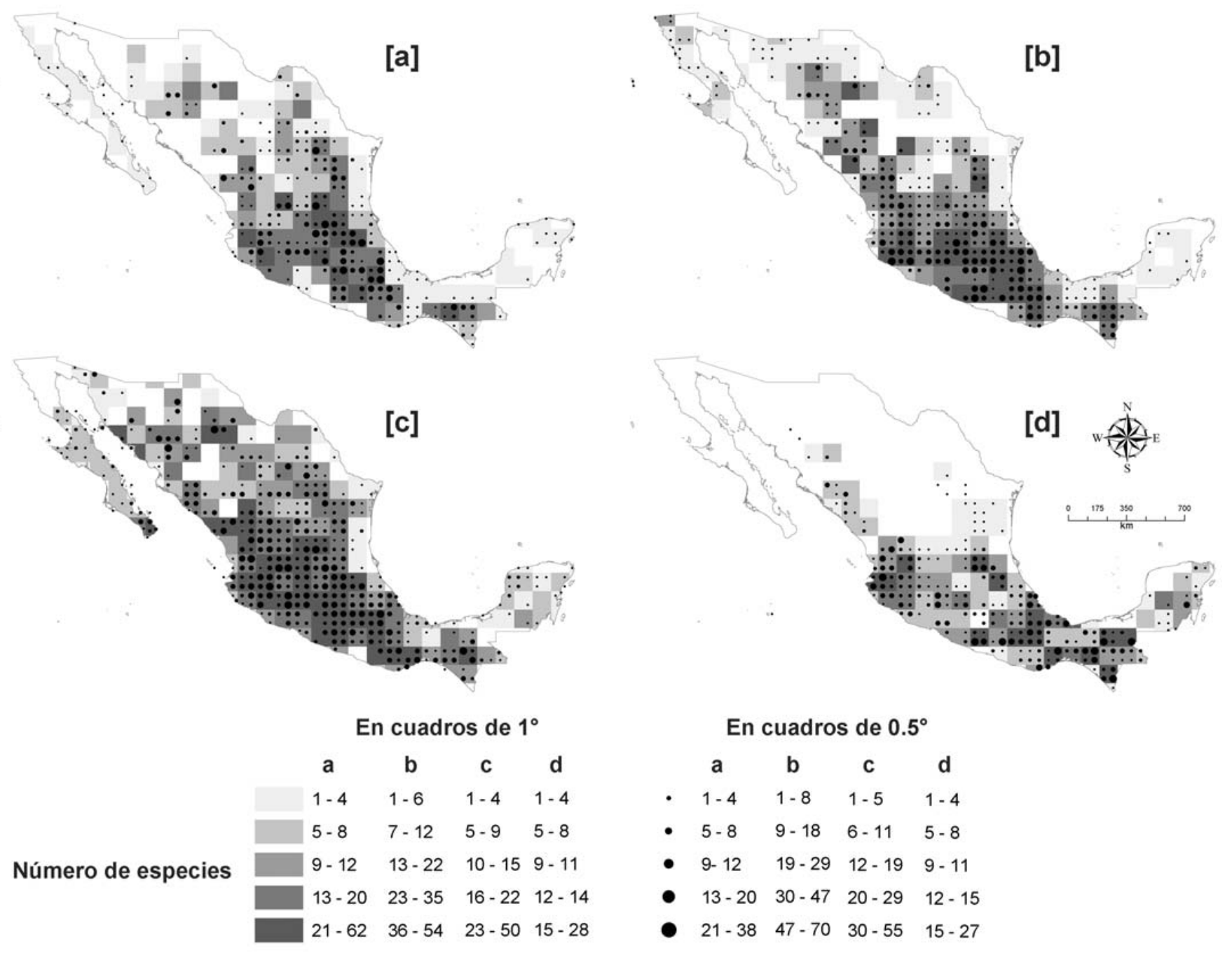

\section{En cuadros de $0.5^{\circ}$}

\begin{tabular}{lllll} 
& $\mathbf{a}$ & $\mathbf{b}$ & $\mathbf{c}$ & \multicolumn{1}{c}{$\mathbf{d}$} \\
- & $1-4$ & $1-8$ & $1-5$ & $1-4$ \\
- & $5-8$ & $9-18$ & $6-11$ & $5-8$ \\
- & $9-12$ & $19-29$ & $12-19$ & $9-11$ \\
- & $13-20$ & $30-47$ & $20-29$ & $12-15$ \\
- & $21-38$ & $47-70$ & $30-55$ & $15-27$
\end{tabular}

Figura 3. Riqueza estimada en las tribus de Asteraceae estudiadas: [a] Mutisieae, [b] Senecioneae, [c] Tageteae, [d] Vernonieae.

$18.3 \%$ del total de especies de Asteraceae reconocidas para México (Villaseñor, 2003). Aunque en este trabajo solamente se están evaluando los patrones de riqueza total, es importante subrayar que $71.4 \%$ de estas especies (395 de 553) son endémicas de México (cuadro 1).

La figura 1 ilustra los patrones de riqueza conocida para cada tribu, con base en los registros de herbario. Se muestran los valores de riqueza por celda tanto a escala de $1^{\circ}$, como de $0.5^{\circ}$. En la figura 2a se muestra la combinación de los datos de todas las tribus. En general se puede afirmar que las especies analizadas se distribuyen en todo el país; sin embargo, por la ubicación de las celdas con mayor diversidad, se observa una tendencia a concentrarse en la porción central y sur de México.

La figura 3 muestra los patrones de riqueza estimada para cada tribu. En ella se ilustran los posibles escenarios de distribución de las especies de las tribus analizadas. También se muestra la posición de los sitios de alta riqueza (hot spots) destacados por el modelo, mismos que pueden ser contrastados con los hot spots definidos a partir del material estudiado (figura 1). En la figura $2 \mathrm{~b}$ se ilustra la combinación de los valores estimados para todas las tribus.

En el cuadro 2 se indica el número de celdas registradas con miembros de las cuatro tribus de Asteraceae analizadas. Para la escala de $1^{\circ}$ se puede observar que, de un total de 263 celdas que cubren el territorio nacional, 199 de ellas (75.7\%) presentan registros de Mutisieae, 189 (71.9\%) de Senecioneae, 233 (88.6\%) de Tageteae y 127 (48.3\%) de Vernonieae. Para la escala de $0.5^{\circ}$, de un total de 876 celdas que cubren la superficie terrestre de México, 479 (54.7\%) presentan registros de Mutisieae, 497 (56.7\%) de Senecioneae, 656 (74.9\%) de Tageteae y 333 (38.0\%) de 
Vernonieae. En conjunto, se tiene que $93.2 \%$ del territorio, según su división en celdas de $1^{\circ}$, registran al menos una especie de estas cuatro tribus, mientras que la proporción equivalente para celdas de $0.5^{\circ}$ es $85.3 \%$. Cuando se evalúan las celdas registradas con riqueza estimada (cuadro 2), se observa una disminución, debido a que varias de ellas se indeterminan, como se indicó previamente. No obstante, es importante subrayar que continúa siendo elevado el porcentaje del territorio $(81.7 \%$ con celdas de un grado y $60.4 \%$ con celdas de medio grado) sobre el cual pueden hacerse estimaciones para las cuatro tribus; estos resultados reflejan el importante esfuerzo que los botánicos han hecho a lo largo del país para documentar su riqueza florística.

En los cuadros 3 y 4 se presenta la distribución de frecuencias de los valores de riqueza conocidos y de los valores estimados para las celdas en que fue dividido México. Para las dos escalas, se observa que la mayoría de las celdas presentan una riqueza conocida sesgada a pocas especies por celdas. Para todas las tribus analizadas, la mayoría de las celdas incluye entre una y cinco especies. La estimación
Cuadro 2. Celdas registradas con al menos una especie de las tribus de Asteraceae analizadas. Entre paréntesis se indica el porcentaje con respecto al total de celdas en que fue dividido México.

\begin{tabular}{lrr}
\hline Tribu & Celdas de $1^{\circ} \times 1^{\circ}$ & Celdas de $0.5^{\circ} \times 0.5^{\circ}$ \\
\hline Riqueza observada & & \\
Mutisieae & $199(75.7)$ & $479(54.7)$ \\
Senecioneae & $189(71.9)$ & $497(56.7)$ \\
Tageteae & $233(88.6)$ & $656(74.9)$ \\
Vernonieae & $127(48.3)$ & $333(38.0)$ \\
Cuatro tribus & $245(93.2)$ & $747(85.3)$ \\
Riqueza estimada & & \\
Mutisieae & & \\
Senecioneae & $147(55.9)$ & $249(28.4)$ \\
Tageteae & $155(58.9)$ & $329(37.6)$ \\
Vernonieae & $185(70.3)$ & $222(25.3)$ \\
Cuatro tribus & $98(37.3)$ & $529(60.4)$ \\
\hline
\end{tabular}

Cuadro 3. Distribución de frecuencias de los valores de riqueza conocida, riqueza estimada y diferencias en las tribus de Asteraceae analizadas utilizando una malla de $1^{\circ} \times 1^{\circ}$ (Mut $=$ Mutisieae, Sen $=$ Senecioneae, Tag $=$ Tageteae, Ver $=$ Vernonieae .

\begin{tabular}{|c|c|c|c|c|c|c|c|c|c|c|c|c|c|c|c|}
\hline \multirow[b]{2}{*}{ Especies } & \multicolumn{5}{|c|}{ Total conocido } & \multicolumn{5}{|c|}{ Estimado con ICE } & \multicolumn{5}{|c|}{ Diferencia (ICE-Total) } \\
\hline & $\overline{\text { Mut }}$ & Sen & Tag & Ver & 4 tribus & $\overline{\text { Mut }}$ & Sen & Tag & Ver & 4 tribus & $\overline{\text { Mut }}$ & Sen & Tag & Ver & 4 tribus \\
\hline Nulo & 0 & 0 & 0 & 0 & 0 & 52 & 34 & 48 & 29 & 30 & 52 & 34 & 48 & 29 & 30 \\
\hline 0 & 0 & 0 & 0 & 0 & 0 & 0 & 0 & 0 & 0 & 0 & 39 & 23 & 24 & 20 & 6 \\
\hline $1-5$ & 151 & 101 & 118 & 78 & 71 & 67 & 46 & 45 & 33 & 25 & 83 & 84 & 116 & 68 & 73 \\
\hline $6-10$ & 28 & 29 & 53 & 31 & 50 & 36 & 30 & 40 & 35 & 22 & 18 & 27 & 26 & 7 & 43 \\
\hline $11-15$ & 15 & 18 & 22 & 18 & 29 & 23 & 15 & 27 & 18 & 25 & 5 & 10 & 12 & 3 & 29 \\
\hline $16-20$ & 4 & 9 & 24 & 0 & 16 & 8 & 13 & 27 & 8 & 18 & 1 & 3 & 3 & 0 & 30 \\
\hline $21-25$ & 0 & 8 & 14 & 0 & 11 & 7 & 9 & 25 & 2 & 19 & 0 & 2 & 0 & 0 & 16 \\
\hline $26-30$ & 1 & 10 & 2 & 0 & 6 & 4 & 9 & 10 & 2 & 16 & 0 & 3 & 2 & 0 & 8 \\
\hline $31-35$ & 0 & 3 & 0 & 0 & 12 & 1 & 8 & 6 & 0 & 12 & 0 & 2 & 2 & 0 & 6 \\
\hline $36-40$ & 0 & 5 & 0 & 0 & 5 & 0 & 11 & 3 & 0 & 7 & 0 & 1 & 0 & 0 & 1 \\
\hline $41-45$ & 0 & 3 & 0 & 0 & 5 & 0 & 2 & 1 & 0 & 5 & 0 & 0 & 0 & 0 & 1 \\
\hline $46-50$ & 0 & 3 & 0 & 0 & 7 & 0 & 7 & 1 & 0 & 10 & 1 & 0 & 0 & 0 & 0 \\
\hline $51-55$ & 0 & 0 & 0 & 0 & 4 & 0 & 5 & 0 & 0 & 8 & 0 & 0 & 0 & 0 & 2 \\
\hline $56-60$ & 0 & 0 & 0 & 0 & 7 & 0 & 0 & 0 & 0 & 6 & 0 & 0 & 0 & 0 & 0 \\
\hline $61-65$ & 0 & 0 & 0 & 0 & 4 & 1 & 0 & 0 & 0 & 5 & 0 & 0 & 0 & 0 & 0 \\
\hline $66-70$ & 0 & 0 & 0 & 0 & 4 & 0 & 0 & 0 & 0 & 6 & 0 & 0 & 0 & 0 & 0 \\
\hline $71-75$ & 0 & 0 & 0 & 0 & 2 & 0 & 0 & 0 & 0 & 7 & 0 & 0 & 0 & 0 & 0 \\
\hline $76-80$ & 0 & 0 & 0 & 0 & 2 & 0 & 0 & 0 & 0 & 3 & 0 & 0 & 0 & 0 & 0 \\
\hline $81-85$ & 0 & 0 & 0 & 0 & 5 & 0 & 0 & 0 & 0 & 3 & 0 & 0 & 0 & 0 & 0 \\
\hline $86-90$ & 0 & 0 & 0 & 0 & 1 & 0 & 0 & 0 & 0 & 0 & 0 & 0 & 0 & 0 & 0 \\
\hline 91-95 & 0 & 0 & 0 & 0 & 3 & 0 & 0 & 0 & 0 & 7 & 0 & 0 & 0 & 0 & 0 \\
\hline $96-100$ & 0 & 0 & 0 & 0 & 0 & 0 & 0 & 0 & 0 & 3 & 0 & 0 & 0 & 0 & 0 \\
\hline $101-105$ & 0 & 0 & 0 & 0 & 1 & 0 & 0 & 0 & 0 & 3 & 0 & 0 & 0 & 0 & 0 \\
\hline $106-110$ & 0 & 0 & 0 & 0 & 0 & 0 & 0 & 0 & 0 & 2 & 0 & 0 & 0 & 0 & 0 \\
\hline $111-115$ & 0 & 0 & 0 & 0 & 0 & 0 & 0 & 0 & 0 & 0 & 0 & 0 & 0 & 0 & 0 \\
\hline $116-120$ & 0 & 0 & 0 & 0 & 0 & 0 & 0 & 0 & 0 & 1 & 0 & 0 & 0 & 0 & 0 \\
\hline $121-125$ & 0 & 0 & 0 & 0 & 0 & 0 & 0 & 0 & 0 & 2 & 0 & 0 & 0 & 0 & 0 \\
\hline Total & 199 & 189 & 233 & 127 & 245 & 199 & 189 & 233 & 127 & 245 & 199 & 189 & 233 & 127 & 245 \\
\hline
\end{tabular}


ESTIMACIÓN DE RIQUEZA DE ASTERACEAE MEDIANTE EXTRAPOLACIÓN

Cuadro 4. Distribución de frecuencias de los valores de riqueza conocida, riqueza estimada y diferencias en las tribus de Asteraceae analizadas utilizando una malla de $0.5^{\circ} \times 0.5^{\circ}$ (Mut $=$ Mutisieae, Sen $=$ Senecioneae, Tag $=$ Tageteae, Ver $=$ Vernonieae .

\begin{tabular}{|c|c|c|c|c|c|c|c|c|c|c|c|c|c|c|c|}
\hline \multirow[b]{2}{*}{ Especies } & \multicolumn{5}{|c|}{ Total conocido } & \multicolumn{5}{|c|}{ Estimado con ICE } & \multicolumn{5}{|c|}{ Diferencia (ICE-Total) } \\
\hline & $\overline{\text { Mut }}$ & Sen & Tag & Ver & 4 tribus & $\overline{\text { Mut }}$ & Sen & Tag & Ver & 4 tribus & $\overline{\text { Mut }}$ & Sen & Tag & Ver & 4 tribus \\
\hline Nulo & 0 & 0 & 0 & 0 & 0 & 230 & 168 & 245 & 111 & 218 & 230 & 168 & 245 & 111 & 218 \\
\hline 0 & 0 & 0 & 0 & 0 & 0 & 0 & 0 & 0 & 0 & 0 & 77 & 58 & 57 & 47 & 30 \\
\hline $1-5$ & 426 & 328 & 449 & 261 & 363 & 144 & 105 & 121 & 101 & 80 & 140 & 166 & 237 & 150 & 184 \\
\hline $6-10$ & 46 & 70 & 128 & 67 & 141 & 63 & 59 & 102 & 90 & 84 & 23 & 57 & 69 & 21 & 115 \\
\hline $11-15$ & 6 & 42 & 61 & 5 & 66 & 26 & 49 & 89 & 23 & 68 & 4 & 28 & 25 & 3 & 67 \\
\hline $16-20$ & 1 & 22 & 16 & 0 & 42 & 8 & 28 & 48 & 6 & 42 & 4 & 8 & 12 & 1 & 45 \\
\hline $21-25$ & 0 & 19 & 2 & 0 & 35 & 3 & 31 & 25 & 1 & 33 & 0 & 5 & 7 & 0 & 33 \\
\hline $26-30$ & 0 & 9 & 0 & 0 & 17 & 3 & 25 & 15 & 1 & 39 & 1 & 1 & 2 & 0 & 20 \\
\hline $31-35$ & 0 & 3 & 0 & 0 & 24 & 1 & 12 & 7 & 0 & 27 & 0 & 2 & 1 & 0 & 9 \\
\hline $36-40$ & 0 & 4 & 0 & 0 & 14 & 1 & 8 & 2 & 0 & 27 & 0 & 0 & 1 & 0 & 11 \\
\hline $41-45$ & 0 & 0 & 0 & 0 & 13 & 0 & 4 & 0 & 0 & 23 & 0 & 0 & 0 & 0 & 3 \\
\hline $46-50$ & 0 & 0 & 0 & 0 & 12 & 0 & 3 & 1 & 0 & 22 & 0 & 2 & 0 & 0 & 5 \\
\hline $51-55$ & 0 & 0 & 0 & 0 & 7 & 0 & 0 & 1 & 0 & 15 & 0 & 1 & 0 & 0 & 3 \\
\hline $56-60$ & 0 & 0 & 0 & 0 & 10 & 0 & 2 & 0 & 0 & 17 & 0 & 1 & 0 & 0 & 1 \\
\hline $61-65$ & 0 & 0 & 0 & 0 & 3 & 0 & 2 & 0 & 0 & 19 & 0 & 0 & 0 & 0 & 1 \\
\hline $66-70$ & 0 & 0 & 0 & 0 & 0 & 0 & 1 & 0 & 0 & 11 & 0 & 0 & 0 & 0 & 1 \\
\hline $71-75$ & 0 & 0 & 0 & 0 & 0 & 0 & 0 & 0 & 0 & 11 & 0 & 0 & 0 & 0 & 1 \\
\hline $76-80$ & 0 & 0 & 0 & 0 & 0 & 0 & 0 & 0 & 0 & 4 & 0 & 0 & 0 & 0 & 0 \\
\hline $81-85$ & 0 & 0 & 0 & 0 & 0 & 0 & 0 & 0 & 0 & 4 & 0 & 0 & 0 & 0 & 0 \\
\hline $86-90$ & 0 & 0 & 0 & 0 & 0 & 0 & 0 & 0 & 0 & 0 & 0 & 0 & 0 & 0 & 0 \\
\hline $91-95$ & 0 & 0 & 0 & 0 & 0 & 0 & 0 & 0 & 0 & 0 & 0 & 0 & 0 & 0 & 0 \\
\hline $95-100$ & 0 & 0 & 0 & 0 & 0 & 0 & 0 & 0 & 0 & 1 & 0 & 0 & 0 & 0 & 0 \\
\hline 101-105 & 0 & 0 & 0 & 0 & 0 & 0 & 0 & 0 & 0 & 1 & 0 & 0 & 0 & 0 & 0 \\
\hline $106-110$ & 0 & 0 & 0 & 0 & 0 & 0 & 0 & 0 & 0 & 1 & 0 & 0 & 0 & 0 & 0 \\
\hline Total & 479 & 497 & 656 & 333 & 747 & 479 & 497 & 656 & 333 & 747 & 479 & 497 & 656 & 333 & 74 \\
\hline
\end{tabular}

con ICE también revela que un alto porcentaje de celdas contiene el mismo intervalo de especies, aunque la proyección sugiere que existen celdas que duplican la máxima riqueza conocida basándose en el material estudiado (por ejemplo Mutisieae y Vernonieae). También hay que subrayar que el sesgo o la marcada asimetría hacia muchas celdas con valores de riqueza bajos (riqueza observada), se ve atenuada en los valores de riqueza estimada: mientras que con la riqueza observada se tienen 174 y 384 celdas con seis o más especies de las cuatro tribus (para las dos escalas utilizadas), al hacer la estimación estos números de celdas se incrementan a 190 y 449, respectivamente.

En los cuadros 3 y 4 también se indica la distribución de frecuencias de los valores de las diferencias entre el valor de ICE y la riqueza conocida. La mayoría de las celdas muestran diferencias de cinco o menos especies (aquí también se incluyen las celdas con diferencia nula o indeterminadas y las de valor cero por la diferencia entre la riqueza conocida y la estimada). Para la cuadrícula de $1^{\circ}$ se registran 136 celdas (de un total de 245) donde la extrapolación sugiere que debería encontrarse un excedente de seis o más especies que las conocidas hasta ahora. Para la cuadrícula de $0.5^{\circ}$, son 315 las celdas (de un total de 747) que contienen seis o más especies por arriba de las conocidas. Tales celdas representan $55.5 \%$ de la cuadrícula de un grado y $42.2 \%$ de la de medio grado.

La figura 4 ilustra cómo se distribuyen los valores de diferencia obtenidos entre la riqueza estimada y la riqueza conocida (cuadros 3 y 4). Como ya se mencionó, los patrones de riqueza observada y estimada concentran las celdas más importantes hacia el centro y sur del país; sin embargo, las diferencias también muestran sitios importantes hacia su porción norte. Tales celdas se identifican como áreas prioritarias para realizar exploraciones en el futuro, dado que las estimaciones sugieren números importantes de especies por adicionar a los valores conocidos en la actualidad. La figura 5 es un mapa de consenso que resume la información contenida en la figura 4 y permite identificar las celdas más importantes para todas las tribus en conjunto.

Las figuras 1-5 destacan las celdas más importantes por el número de especies que contienen o pudieran contener. 


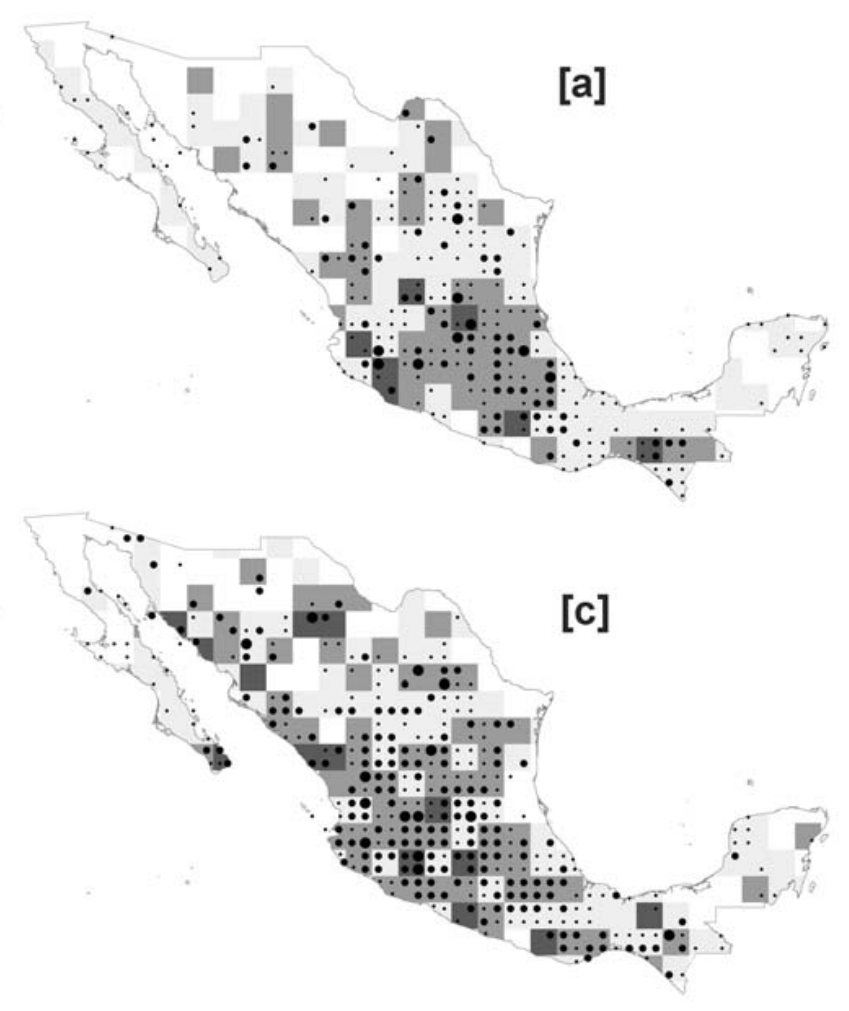

En cuadros de $1^{\circ}$

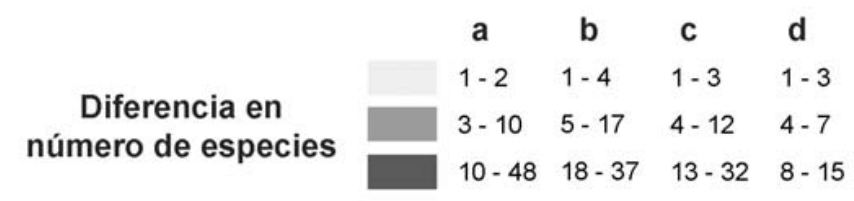

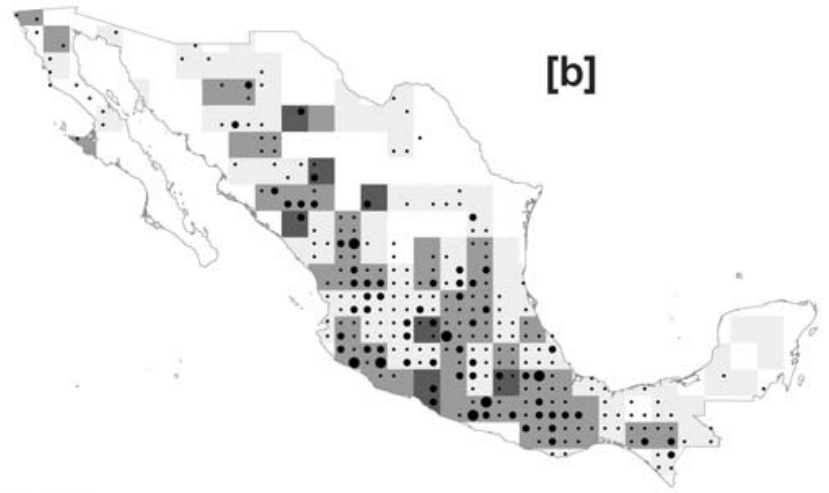

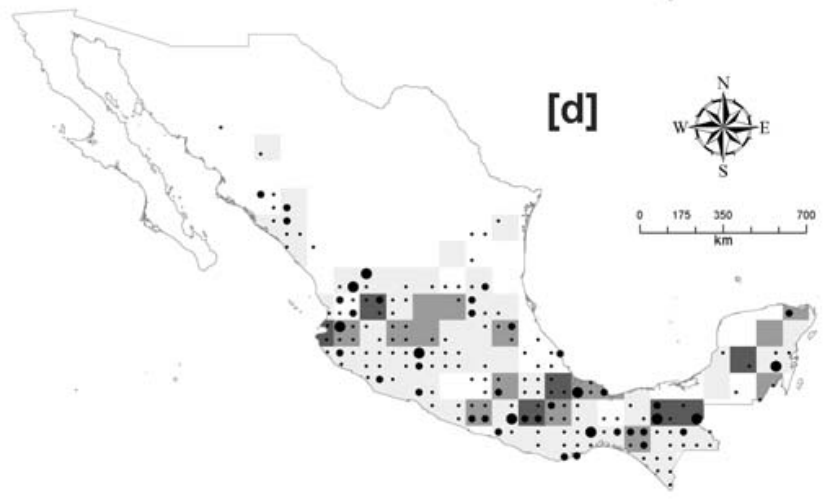

En cuadros de $0.5^{\circ}$

$\begin{array}{ccccc} & \mathbf{a} & \mathbf{b} & \mathbf{c} & \mathbf{d} \\ \text { - } & 1-2 & 1-8 & 1-3 & 1-3 \\ \text { - } & 3-10 & 9-24 & 4-18 & 4-7 \\ \text { - } & 10-31 & 25-57 & 18-36 & 7-19\end{array}$

Figura 4. Número de especies obtenido de la diferencia entre la riqueza estimada y la riqueza observada en las tribus de Asteraceae estudiadas: [a] Mutisieae, [b] Senecioneae, [c] Tageteae, [d] Vernonieae.

Sin embargo, es necesario hacer una selección más precisa de las celdas que en el futuro pudieran representar sitios prioritarios de exploración, o bien para seleccionarlas como sitios a conservar por su alta riqueza de especies. Para ello se seleccionaron, de entre todas las celdas, aquellas que presentaron valores superiores al promedio (más una desviación estándar), tanto de riqueza conocida y de riqueza estimada, como de sus diferencias. En el cuadro 5 se indica el número de celdas que cumplieron con este requisito y su importancia en función del número de tribus para el que son relevantes.

Para la escala de $1^{\circ}$ se identifican 50 celdas importantes por su riqueza observada, 54 por su riqueza estimada y 60 por su diferencia (cuadro 5). Por su riqueza observada, seis celdas se identifican como importantes para las cuatro tribus evaluadas, ocho para tres, 15 para dos y 21 para una sola. Al hacer las estimaciones de diversidad, el número de
Cuadro 5. Número de celdas seleccionadas por su importancia como hot spots o por su valor de diferencia y número de tribus para las que son importantes. Las celdas seleccionadas presentaron valores superiores al promedio (más una desviación estándar) de riqueza observada (total de especies), riqueza estimada (ICE) y de diferencia entre la riqueza estimada y observada.

\begin{tabular}{ccrc}
\hline Número tribus & Total especies & ICE & Diferencia ICE-Total \\
\hline Malla $\mathbf{1}^{\circ} \times \mathbf{1}^{\circ}$ & & & \\
1 & 21 & 29 & 52 \\
2 & 15 & 13 & 8 \\
3 & 8 & 9 & \\
4 & 6 & 3 & \\
Total & 50 & 54 & 60 \\
Malla $\mathbf{0 . 5} \mathbf{0}^{\circ} \mathbf{0 . 5}$ & & & \\
1 & 50 & 77 & 96 \\
2 & 33 & 33 & 22 \\
3 & 12 & 8 & 1 \\
4 & 4 & 1 & 0 \\
Total & 99 & 119 & 119 \\
\hline
\end{tabular}




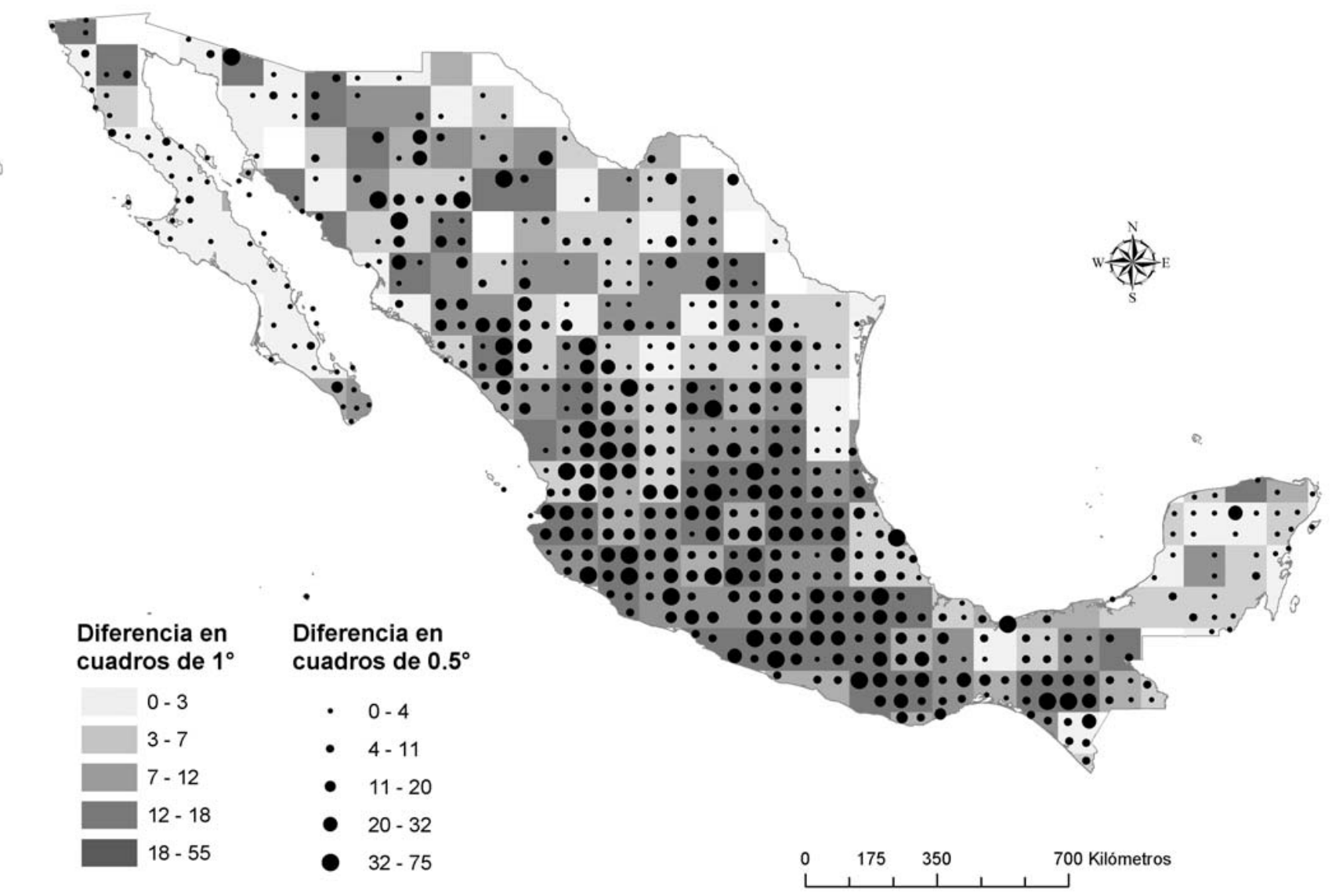

Figura 5. Número de especies obtenido de la diferencia entre la riqueza estimada y la riqueza observada en las tribus de Asteraceae estudiadas.

hot spots no se incrementa substancialmente, pues sólo se adicionan cuatro celdas más; lo relevante es que sólo se identifican tres celdas importantes para las cuatro tribus en conjunto y nueve para tres tribus. Finalmente, las diferencias permiten detectar 52 celdas relevantes para una sola tribu y ocho para dos.

Para la escala de $0.5^{\circ}$ se identifican 99 celdas importantes por su riqueza observada, 119 por su riqueza estimada y 119 por su diferencia (cuadro 5). Por su riqueza observada, cuatro celdas se identifican como importantes para las cuatro tribus evaluadas, 12 para tres, 33 para dos y 50 para una sola. Por su riqueza estimada, una sola celda se revela como importante para las cuatro tribus y ocho para tres; por otra parte, de acuerdo con sus diferencias, solamente se identifica una celda como importante para tres tribus y 22 para dos.

La figura 6 muestra gráficamente, para la escala de $0.5^{\circ}$, la ubicación de las celdas identificadas como sitios importantes por sus valores de diversidad conocida y estimada o de diferencia. La figura 6 a muestra los hot spots de riqueza conocida y la figura $6 \mathrm{~b}$ los de riqueza estimada. En la figu- ra 7 se identifican las celdas con mayor diferencia entre la riqueza estimada y la conocida. En la figura 6a se puede ver, por ejemplo, que las cuatro celdas que destacaron como hot spots para las cuatro tribus, se ubican una en la porción central de Jalisco y las otros tres en la porción norte y occidental de Oaxaca. A su vez, la celda más importante por su riqueza estimada (figura $6 b$ ), ya que incluye las cuatro tribus, igualmente se localiza en la porción norte de Oaxaca y es la misma que una de las cuatro identificadas por su riqueza conocida. Finalmente, la celda más importante por la diferencia entre la riqueza estimada y la riqueza conocida se ubica en la porción centro-oriental del estado de Chiapas (figura 7).

\section{Discusión}

La bibliografía muestra que, al menos en los últimos tres lustros, se ha trabajado intensamente para contestar la pregunta de cuál es la riqueza vegetal de México. Sin embargo, no ha habido consenso, principalmente debido a que los distintos enfoques para estimar tal riqueza por lo general 

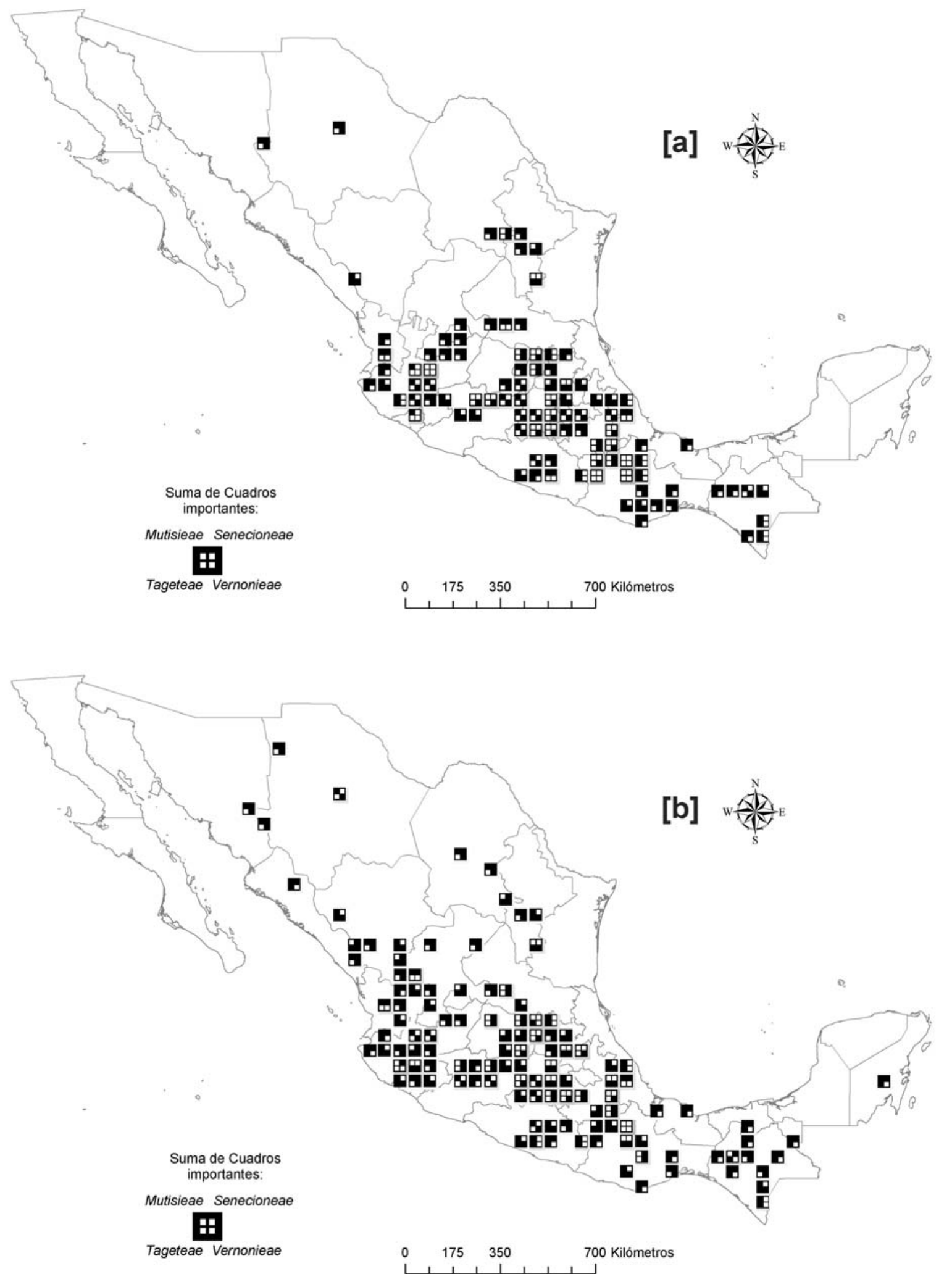

Figura 6. Celdas importantes (hot spots) por su número de especies conocidas [a] y por su número de especies estimadas [b] para las cuatro tribus de Asteraceae estudiadas (tamaño de la celda: $0.5^{\circ} \times 0.5^{\circ}$ ). 


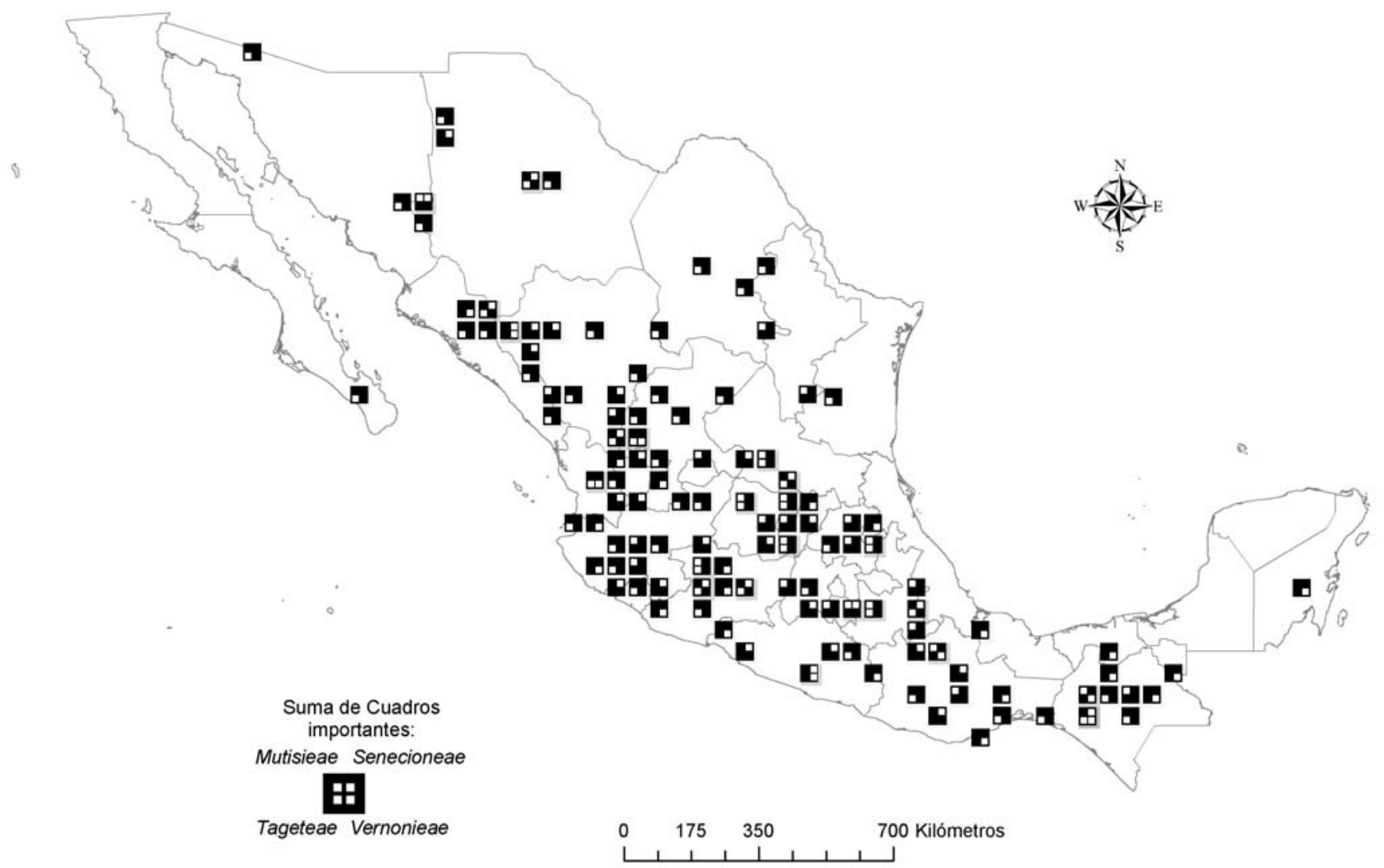

Figura 7. Celdas importantes por los valores de diferencia entre la riqueza estimada y la riqueza observada para las cuatro tribus de Asteraceae estudiadas (tamaño de la celda: $0.5^{\circ} \times 0.5^{\circ}$ ).

arrojan diferentes cifras (ver por ejemplo Villaseñor, 2003 para una discusión de diferentes estimaciones de la riqueza de angiospermas y Espejo-Serna et al., 2004 para otra cifra adicional). Estos ejercicios son importantes, pues aunque algunas personas subrayan que es en los herbarios y en los museos de historia natural donde se encuentra la información más completa y confiable para estudiar, bajo diversos enfoques, a la mayoría de las especies (Nielsen y West, 1994; Ponder et al., 2001), siempre existirán especies que no han sido recolectadas y registradas en las colecciones. Por lo tanto, es necesario hacer predicciones de la proporción de especies no recolectadas, para obtener una estimación más precisa de la verdadera riqueza de especies de la región de interés (Meier y Dikow, 2004).

En la actualidad es posible hacer ejercicios de estimación de la riqueza biológica porque se cuenta con información significativa, en bases de datos. Sin embargo, el control de calidad de esos datos se vuelve cada día más importante, pues conforme se incrementa la cantidad de información, la calidad puede verse disminuida. Los tres problemas principales reconocidos por Soberón y Peterson (2004) y que disminuyen la calidad de los datos por analizar son: (1) la determinación errónea de los especímenes recolectados, (2) la taxonomía base para nombrar a los especímenes puede ser obsoleta, desfasada de los estudios sistemáticos recientes y más robustos, y (3) la localización imprecisa de los sitios de recolecta. En este trabajo se realizaron esfuerzos por minimizar tales errores; por ejemplo, todos los ejemplares utilizados en el análisis fueron determinados por uno de nosotros (José Luis Villaseñor), quien lleva más de 15 años estudiando la taxonomía de las Asteraceae mexicanas. Por otra parte, las coordenadas geográficas de los sitios de recolecta fueron verificadas mediante los recursos de cómputo que la CONABIO ha elaborado para validar, en la medida de lo posible, la posición geográfica correcta del sitio georreferenciado (recursos incorporados en el programa Biótica 4.1; Anónimo 2003). Como ya se dijo, la mayoría de los ejemplares utilizados en este análisis y las coordenadas geográficas de sus sitios de recolecta pueden ser consultados en la REMIB (Red Mundial de Información Biológica), en la página de Internet de la CONABIO.

Para la escala de $1^{\circ}$, la mayoría de las celdas muestran un esfuerzo de recolecta satisfactorio; solamente 60 (22.9\% 
José Luis Villaseñor, Pedro Maeda, J. JaVier Colín-LóPez y EnRiQue Ortiz

del total) se destacan como celdas que requieren trabajo de campo adicional, pues registran más especies que el umbral utilizado (promedio más una desviación estándar). A escala de $0.5^{\circ}, 120$ celdas $(13.7 \%$ del total) resaltan como importantes para trabajo de campo futuro. En esta última escala, el esfuerzo de recolecta no se manifiesta tan satisfactorio, pues se observan sitios a todo lo largo del territorio nacional donde se necesitan esfuerzos adicionales para documentar mejor su riqueza florística. Al comparar los valores de riqueza estimada con los de riqueza observada, se detectan sitios que pueden servir de guía para planear mejor el trabajo de campo y así corregir las diferencias encontradas (figura 6). Las diferencias entre los valores observados (total de especies) y estimados pueden servir para justificar este esfuerzo adicional de trabajo de campo en aquellas áreas que los resultados sugieren estar pobremente exploradas (figura 7).

Para la escala de $0.5^{\circ}$ se observó una pérdida de información por la fragmentación de los datos, lo que ocasionó a su vez un mayor número de celdas indeterminadas al utilizar ICE. La razón de esto es que no necesariamente existen muestreos que reflejen la heterogeneidad ambiental de la zona de estudio; mientras más grande el área, existe una probabilidad mayor de que los muestreos reflejen dicha heterogeneidad, pero al reducir el tamaño de las celdas, la probabilidad de muestreos únicos se incrementa mientras se decrementa la de tener más de un muestreo con especies infrecuentes. Sin embargo, para esta escala también se advirtió que el número de especies estimado en promedio es mayor que en las celdas de un grado, lo que da como resultado una ganancia en la delimitación de áreas con mayor riqueza (cuadros 3 y 4). Con este tamaño de celdas se pueden identificar con mayor precisión los centros de concentración de especies, los cuales en el futuro podrán evaluarse para saber, por ejemplo, si también son sitios de concentración de especies endémicas o importantes para otros grupos vegetales y animales. Tal información sin duda incrementará su valor como sitios prioritarios para su conservación.

El uso de dos tamaños de cuadrícula permitió, a una escala macroecológica, dar un panorama general de la riqueza de especies conocida y potencial de las cuatro tribus analizadas. El objetivo de utilizar una escala mayor $\left(0.5^{\circ}\right)$ fue disminuir el área de búsqueda de zonas de interés para estudios posteriores, sin pretender evaluar ni discutir el tamaño óptimo de celda para el conjunto de datos analizado. La cuadrícula de $0.5^{\circ}$, además de revelar que la información existente es insuficiente, hace patente la ausencia de dos componentes necesarios para los cálculos de riqueza potencial mediante el uso del ICE: el número adecuado de repeticiones y la falta de heterogeneidad en las muestras. No obstante estos problemas, los resultados muestran un panorama adecuado para estos cuatro grupos a nivel nacional; para la escala de $1^{\circ}, 93.2 \%$ del territorio registra al menos una especie de estas cuatro tribus, mientras que para la de $0.5^{\circ}$ el territorio cubierto es $85.3 \%$. Al hacer las estimaciones, $81.7 \%$ con celdas de un grado y $60.4 \%$ con celdas de medio grado se recuperan como celdas con información relevante. Tales resultados pueden ser comparados con los de Oñate et al. (2000), quienes sin hacer modelación con ICE, y dividiendo también a México en celdas de $0.5^{\circ}$ por lado, encuentran que $60 \%$ de ellas registran al menos una especie de Lepidópteros.

Los estimadores de riqueza, como el que aquí se utilizó, solamente proporcionan datos acerca de cuántas especies podrían existir en un sitio determinado, pero no proporcionan datos específicos acerca de cuáles especies son. Esta información deberá obtenerse con el trabajo florístico y taxonómico rutinario. Sin embargo, tales datos son de mucho valor para optimizar los escasos recursos materiales $\mathrm{y}$ humanos con que se dispone. Al hacer una mejor selección de los sitios a explorar, indudablemente los recursos serán más eficientes y se podrá lograr en menos tiempo la meta de tener una aproximación mayor de la riqueza florística y delimitar mejor las áreas donde se concentra.

El uso de los datos de riqueza de especies, como substituto de la biodiversidad real para predecir la importancia de un sitio, permite avanzar en una estrategia de conservación de esta biodiversidad. Subsecuentemente, tal estrategia deberá sustentarse en trabajo de campo adicional, que verifique su robustez y la condición actual del área seleccionada, para después aplicar los principios y métodos que ha definido la biología de la conservación en la delimitación más precisa de las áreas a conservar. Con base en la metodología aplicada en este trabajo, las áreas obtenidas como de alta riqueza de especies, o de alto valor de diferencia entre la riqueza estimada y la riqueza conocida, pueden servir como la primera etapa mencionada; la verificación posterior, con trabajo de campo, sustentará las predicciones teóricas. Una vez definidas como sitios de gran valor biológico, se pueden proponer como sitios prioritarios para establecer las medidas de control y manejo, que cualquier sitio requiere para conservar a largo plazo la biodiversidad existente.

En la actualidad México carece de un programa nacional efectivo para la conservación de su alta riqueza biológica. Lo más cercano a este programa de conservación es la lista de especies en riesgo incluida en la norma NOM-059ECOL-2001 (Secretaría de Medio Ambiente y Recursos Naturales, 2002), que identifica aquellas especies que requieren programas de atención o rescate para evitar su extinción. Sin embargo, la NOM solamente incluye unas 900 especies de plantas vasculares (eliminando sinonimias) y en la flora de México existen muchas que no han sido incluidas y otras más lo estarán en un futuro próximo, debido al impacto negativo sobre sus ambientes naturales por las actividades humanas. Sin embargo, existe preocupación pues prácticamente es imposible llevar a cabo 
estrategias de manejo y conservación de especies individuales, como sería el caso de cada una de las especies incluidas en la NOM.

Otra actividad, que no es parte de un programa de conservación de la biodiversidad mexicana, es la detección de un conjunto de regiones terrestres prioritarias (ArriagaCabrera et al., 2000). Sin embargo, estudios recientes en grupos vegetales como Cucurbitaceae (Lira et al., 2002) o Asteraceae (Villaseñor et al., 2004), revelan que tales áreas, no obstante que comprenden una parte substancial del territorio nacional, dejan afuera muchas especies, sobre todo endémicas. Si se determinan las estrategias de conservación con base en tales regiones, sin lugar a dudas quedarán sin atención muchas especies y sitios igualmente relevantes. Por lo tanto, en este momento es imposible pensar en estrategias eficientes de conservación de nuestra biodiversidad si no se conocen mejor algunos de los elementos representados en las áreas a manejar, como es su riqueza de especies. Los modelos cuantitativos de extrapolación de la biodiversidad, dentro del que se inscribe el método utilizado en este trabajo (ICE) o el uso de otros métodos de estimación no paramétricos, sin duda ayudarán a identificar las áreas potenciales donde estarían mejor representados uno de los componentes primarios de la biodiversidad: las especies.

\section{Agradecimientos}

El primer autor agradece la amistad y el apoyo logístico y económico de Theodore M. Barkley†, William R. Anderson y Thomas S. Elias, cuando se estudiaron diferentes colecciones botánicas en los Estados Unidos. El Instituto de Biología de la UNAM y la CONABIO (proyectos Q069, U004, V040 y BE007) apoyaron con recursos económicos, humanos y materiales. Agradecemos a Francisco Espinosa, Jorge Llorente, Enrique Martínez, Jorge Meave y Oswaldo Téllez la lectura del manuscrito y sus importantes comentarios para mejorarlo.

\section{Literatura citada}

Anónimo. 2003. Biótica 4.1. Sistema de Información Biótica. Manual de Usuario. Fideicomiso Fondo para la Biodiversidad, CONABIO, México, D.F.

Arriaga-Cabrera L., Espinosa-Rodríguez J.M., Aguilar-Zúñiga C., Martínez-Romero E., Gómez-Mendoza L. y Loa-Loza E. 2000. Regiones Terrestres Prioritarias de México. Comisión Nacional para el Conocimiento y Uso de la Biodiversidad, México, D.F.

Cabrera-Rodríguez L. y Villaseñor J.L. 1987. Revisión bibliográfica sobre el conocimiento de la familia Compositae en México. Biotica 12:131-147.

Colwell R.K. 1997. Estimates: statistical estimation of species richness and shared species from samples. Version 5. Guía de usuario y aplicación publicada en: <http://viceroy.eeb. uconn.edu/estimates>
Colwell R.K. y Coddington J.A. 1994. Estimating terrestrial biodiversity through extrapolation. Philosophical Transactions of the Royal Society, London (Series B) 345:101-118.

Espejo S.A., López-Ferrari A.R. y Salgado-U. I. 2004. A current estimate of angiosperm diversity in Mexico. Taxon 53:127130.

Fagan W.F. y Kareiva. P.M. 1997. Using compiled species lists to make biodiversity comparisons among regions: a test case using Oregon butterflies. Biological Conservation 80:249-259.

Gaston K.J. 1996. Biodiversity: A Biology of Numbers and Difference. Blackwell Science, Oxford.

Hammond P. 1992. Species inventory. En: Groombridge B. Ed. Global Biodiversity: Status of the Earth's Living Resources, pp. 17-39, Chapman \& Hall, Londres.

Lira R., Villaseñor J.L. y Ortiz E. 2002. A proposal for the conservation of the family Cucurbitaceae in Mexico. Biodiversity and Conservation 11:1699-1720.

May R.M. 1992. How many species inhabit the Earth? Scientific American 267:42-48.

Meier R. y Dikow T. 2004. Significance of specimen databases from taxonomic revisions for estimating and mapping the global species diversity of invertebrates and repatriating reliable specimen data. Conservation Biology 18:478-488.

Mittermeier R.A. 1988. Primate diversity and the tropical forest. En: Wilson E.O. Ed. Biodiversity, pp. 145-154, National Academy Press, Washington, D.C.

Mittermeier R.A. y Goettsch de Mittermeier C. 1992. La importancia de la diversidad biológica de México. En: Sarukhán J. y Dirzo R. Comps. México Ante los Retos de la Biodiversidad, pp. 63-73, Comisión Nacional para el Conocimiento y Uso de la Biodiversidad, México, D.F.

Murguía M. y Villaseñor J.L. 2000. Estimating the quality of the records used in quantitative biogeography with presenceabsence matrices. Annales Botanici Fennici 37:289-296.

Nielsen E.S. y West J.G. 1994. Biodiversity research and biological collections: transfer of information. En: Forey P.L., Humphries C.J. y Vane-Wright R.I. Eds. Systematics and Conservation Evaluation, pp. 101-121, Systematics Association Special Volume No. 50, Clarendon Press, Oxford.

Oñate-Ocaña L., Morrone J.J. y Llorente-Bousquets J.E. 2000. Una evaluación del conocimiento y de la distribución de las Papilionidae y Pieridae mexicanas (Insecta: Lepidoptera). Acta Zoologica Mexicana (n.s.) 81:117-132.

Palmer M.W. 1990. The estimation of species richness by extrapolation. Ecology 71:1195-1198.

Palmer M.W. 1991. Estimating species richness: the second-order jackknife reconsidered. Ecology 72:1512-1513.

Petersen F.T., Meier R. y Nykjaer M. 2003. Testing species richness estimation methods using museum label data on the Danish Asilidae. Biodiversity and Conservation 12:687-701.

Ponder W.F., Carter G.A., Flemons P. y Chapman R.R. 2001. Evaluation of museum collection data for use in biodiversity assessment. Conservation Biology 15:648-657.

Secretaría de Medio Ambiente y Recursos Naturales. 2002. Norma Oficial Mexicana NOM-059-ECOL-2001, Protección ambiental-Especies nativas de México de flora y fauna silvestres-Categorías de riesgo y especificaciones para su inclusión, exclusión o cambio-Lista de especies en riesgo. Diario Oficial de la Federación. Miércoles 6 de marzo de 2002, pp. 2-56. 


\section{José Luis Villaseñor, Pedro Maeda, J. JaVIER Colín-LóPeZ y EnRIQue OrtiZ}

Soberón J. y Llorente J. 1993. The use of species accumulation functions for the prediction of species richness. Conservation Biology 7:480-488.

Soberón J., Llorente J. y Oñate L. 2000. The use of specimenlabel databases for conservation purposes: an example using Mexican Papilionid and Pierid butterflies. Biodiversity and Conservation 9:1441-1466.

Soberón J. y Peterson A.T. 2004. Biodiversity informatics: managing and applying primary biodiversity data. Philosophical Transactions of the Royal Society, London (Series B) 359:689698.

Sosa V. y Dávila P. 1994. Una evaluación del conocimiento florístico de México. Annals of the Missouri Botanical Garden 81:749-757.

Soulé M.E. 1990. The real work of systematics. Annals of the
Missouri Botanical Garden 77:4-12.

Villaseñor J.L. 1993. La Familia Asteraceae en México. Revista de la Sociedad Mexicana de Historia Natural Vol. Esp. XLIV:117-124.

Villaseñor J.L. 2003. Diversidad y distribución de las Magnoliophyta de México. Interciencia 28:160-167.

Villaseñor J.L. 2004. Los géneros de plantas vasculares de la flora de México. Boletín de la Sociedad Botánica de México 75:105-135.

Villaseñor J.L., Ortiz E. y Juárez V. 2004. Asteráceas. En: GarcíaMendoza A.J., Ordoñez M.J. y Briones-Salas M. Eds. Biodiversidad de Oaxaca, pp. 177-192, Instituto de BiologíaUNAM-Fondo Oaxaqueño para la Conservación de la Naturaleza-World Wildlife Fund, México, D.F.

Fecha de recepción: 1 de febrero de 2005

Versión corregida: 27 de abril de 2005

Aceptado: 27 de abril de 2005 